\title{
Nest distribution and nest habitat of the Tibetan Partridge (Perdix hodgsoniae) near Lhasa, Tibet
}

\author{
Tsering Dorge ${ }^{1,2}$, Göran Högstedt ${ }^{1}$ and Terje Lislevand ${ }^{3 *}$
}

\begin{abstract}
Background: Little is hitherto known about the breeding ecology of the Tibetan Partridge (Perdix hodgsoniae) which is endemic to the Tibetan plateau. Here we describe nest densities, inter-nest distances and general nest site characteristics in this gallinaceous bird species and explore the possibilities that certain shrub and plant types are preferred as nest surroundings.

Method: A total of 56 nests were found over three breeding seasons near Lhasa, Tibet. Nest site characteristics were compared with random control plots and the proportions of specific plant species covering nests were compared with their estimated general occurrence in the study area.

Results: Nest density in the two years with highest search effort was estimated at $1.43 / \mathrm{km}^{2}$ and $1.04 / \mathrm{km}^{2}$ but was clearly higher in the part of the study area facing north $\left(1.86-2.35 / \mathrm{km}^{2}\right)$ than that facing south $\left(0.11-0.34 / \mathrm{km}^{2}\right)$. The average nearest neighbour distance of nests was about $300 \mathrm{~m}$. Nests were situated in relatively lush vegetation and covered by a total of eight shrub species and three herbs. In contrast to previous reports, Caragana shrub did not constitute an important part of the nest habitat. The flowering, non-thorny bush Potentilla fruticosa was significantly over-represented as nest cover, while Rhododendron nivale was similarly under-represented. Nest bush foliage covered a larger area of ground, and the shrub surrounding nests was generally denser, than in control samples. Also, nests were placed closer to paths and in areas with lower densities of Yak (Bos grunniens) dung than in control samples. Except that soil temperatures were lower on nest sites than on control sites, micro-climate variables measured in this study did not differ between nest sites and control plots.

Conclusions: Opportunity for nest concealment is probably an important quality of the nest habitat in Tibetan Partridges, yet it is unclear why the species should prefer $P$. fruticosa as nest cover. It is possible that nest sites are chosen to secure escape exits in the case of approaching predators and to reduce the risk of nest trampling. Tibetan Partridges may also select nest sites according to micro-climate, either directly or indirectly through climate-related differences in shrub vegetation.
\end{abstract}

Keywords: Himalaya, Nest site selection, Phasianidae, Potentilla fruticosa

\section{Background}

Choosing a proper nest site is critical to breeding birds because characteristics of such sites may influence risks of predation (on both parents, eggs and young in the nest; Martin, 1993; Eggers et al. 2006; Lima, 2009), parasite infection (Larison et al. 1998; Loye and Carroll, 1998), and nest destruction (e.g. by flooding or trampling by mammals in ground nests; Montevecchi, 1978; Koerth et al. 1983; Beintema and Müskens, 1987; Storey

\footnotetext{
*Correspondence: terje.lislevand@um.uib.no

${ }^{3}$ University Museum of Bergen, University of Bergen, Box 7800, 5020 Bergen, Norway

Full list of author information is available at the end of the article
}

et al. 1988; Paine et al. 1996; Watson et al. 2006). The nest site may also have influence on environmental conditions for embryo development and energetic costs of incubation in parent birds (Deeming, 2002; Kim and Monaghan, 2005; D'Alba et al. 2011). Hence, birds should be selected for choosing nest sites in relation to these factors that could have an influence on their life histories (Martin, 1995). Since the relative importance of factors which could affect breeding success varies geographically, between habitats and in relation to a species' ecology there is a considerable inter-specific variation in avian nest site preferences (e.g. Martin, 1995). Studies of nest habitats are 
essential both to improve our understanding of how such variation evolved, to gain insight into a species' basic breeding biology and for conservation purposes.

Traditionally little was known about the nesting biology of birds breeding on the Tibetan Plateau. Although recent studies considerably increased our knowledge about this alpine bird fauna ( $\mathrm{Lu}$ et al. 2010 and references therein), there is still a lot to learn about many Tibetan bird species. One example is the Tibetan Partridge (Perdix hodgsoniae), a gallinaceous bird endemic to the Himalayas. This species occurs commonly and widely distributed across the Tibetan Plateau on altitudes between $3600 \mathrm{~m}$ and $5600 \mathrm{~m}$ (Johnsgard, 1988; del Hoyo et al. 1994; Madge and McGowan, 2002; BirdLife International, 2014). The species' breeding biology is scarcely known, but males are apparently territorial and socially monogamous ( $\mathrm{Lu}$ et al. 2003). Nests are built on the ground, eggs are laid in MayJuly and only females incubate (del Hoyo et al. 1994; Lu et al. 2003; Dorge, 2014). Nests are said to be typically found within Caragana shrub (Madge and McGowan, 2002). A more detailed study by $\mathrm{Lu}$ et al. (2003) showed that the species prefers to nest in patches of low shrub, and sparse, secondary plant cover, but no further information about plant species was given. Nests were often located close to paths, perhaps making it easier for the incubating hen to flee the nest if potential predators appeared (Lu et al. 2003). To our knowledge, quantitative assessments of nest plant preferences and data on spatial distribution of nests are not previously reported in this species.

The purpose of this study was therefore to expand upon the study by Lu et al. (2003) and increase our knowledge about the breeding density and nest habitat in the Tibetan Partridge. We describe nest densities, inter-nest distances and general nest site characteristics.
Thereafter we explore the possibilities that the species prefers to nest in certain types of shrub and if it prefers certain plants as nest cover. For instance, if nest concealment and protection from predators is important in nest-site selection, thorny and/or dense bushes may be selected as nest concealment (Martin, 1993; Filliater et al. 1994; DeLong et al. 1995; Tryjanowski et al. 2000; Remeš, 2005). Further, grazing livestock, particularly Yak (Bos grunniens), were common in our study area. We therefore tested if partridges tended to nest away from grazed areas by comparing the densities of yak dung around nests with random samples. Finally, the highaltitude Himalayan environment is relatively cold for breeding birds, especially in early spring. We therefore checked if nests were located at microclimatic favorable spots.

\section{Methods}

\section{Study area}

The study was carried out at Tukchak in Gyama valley, Meltrokongkar county, Tibet $\left(29^{\circ} 41.095^{\prime} \mathrm{N}, 91^{\circ} 40.423^{\prime} \mathrm{E}\right)$ in 2005, 2009 and 2010. Here, the average annual temperature was $6.5^{\circ} \mathrm{C}$ and annual precipitation was about $600 \mathrm{~mm}$ in the period 2000-2007 (data from the Meltrokongkar county meteorological station). The study area is situated at an altitude of approx. 4100-5000 $\mathrm{m}$ and consists of a valley with two major hill sides facing towards north and south. The south-facing slope is steeper, dryer and warmer than the north-facing slope. In between were some smaller slopes facing in a more easterly or westerly direction. Vegetation in these slopes largely resembled that of the north-facing slope. A representative part of the north-facing slope where we located most nests is shown in Figure 1.

In June 2005, before most nests were found, we carried out a basic vegetation survey in the study area in an attempt to get a general overview of the plant species that

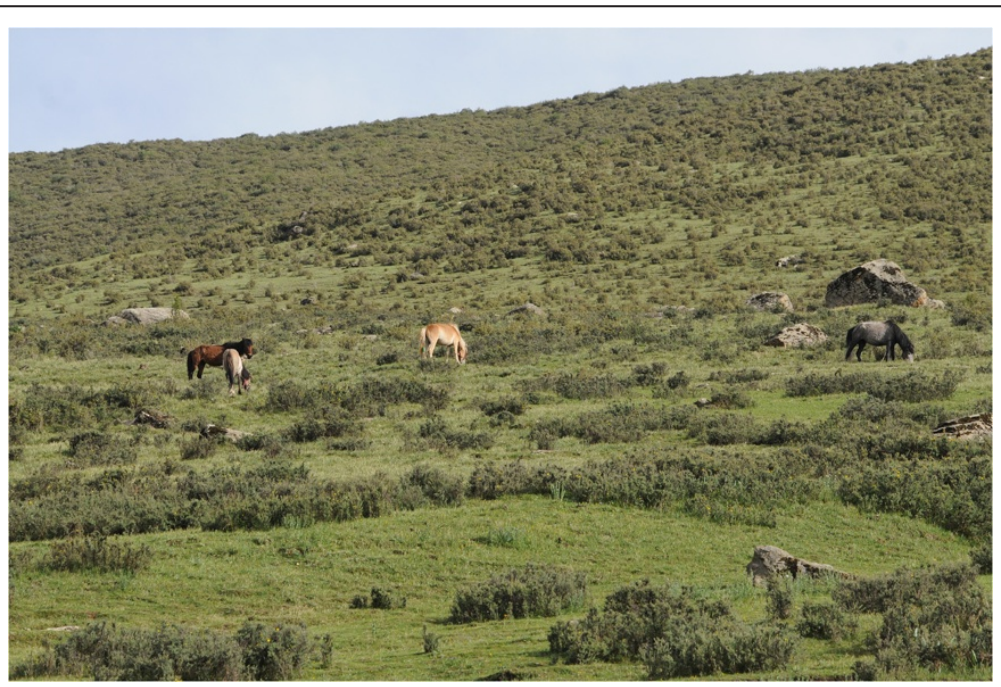

Figure 1 Breeding habitat of the Tibetan Partridge. A part of the north-facing slope where nests were found in Gyama valley near Lhasa, Tibet. 
grew there and their density. This was done in 12 squares in each of the south- and north-facing slopes (i.e. a total of 24 squares). The vegetation survey followed two transect lines situated at the approximate centre-lines of the slopes and stretching from the bottom of the valley and up towards the highest point. The surveyed squares were distributed along these transect lines with neighbouring points being separated by approximately 100 meters of altitude, as indicated by a Garmin eTrex ${ }^{\circledR}$ GPS. Within each square we measured densities of shrub and herbs within areas of $5 \times 5 \mathrm{~m}$ and $1 \times 1 \mathrm{~m}$, respectively. Six species of shrub were recorded on the north-facing slope, of which the most common were Rhododendron primulaeflorum, R. nivale, Salix oritrepha and Potentilla fruticosa. This differed markedly from the southfacing slope where we recorded seven species of shrub and where the species Spiraea tibetica, Potentilla fruticosa, and Sabina pingii dominated in numbers. Bush density (number of bushes $/ 25 \mathrm{~m}^{2}$ ) was higher on the north-facing slope than on the south facing slope (north-facing slope: $12.58 \pm 6.3$, south-facing slope: $9.07 \pm$ 5.90; two-sample t-test: $t=2.34, \mathrm{df}=22, p=0.03$ ). Thorny bush species were mainly distributed on the south-facing slope and included Rosa sericea, Berberis hemleyana, Caragana maximovicziana and C. jubata. In total 31 species of herbs were recorded in the north-facing slope and 28 species in the south-facing slope, of which 16 species occurred in both slopes. There were no significant differences in herb densities (number of individual plants $/ \mathrm{m}^{2}$ ) between north-facing and south-facing slopes (north-facing slope: $30.99 \pm 122.71$, south-facing slope: $14.10 \pm 52.5$; two-sample t-test: $t=0.91$, $\mathrm{df}=22, P=0.37$ ).

Gyama is one of the most important animal husbandry regions for Lhasa Prefecture and the study area has probably been used by grazing livestock for a very long time. Major livestock today are horses, yak, sheep, goat and cattle. Some wild mammals are also commonly grazing in the area, for instance Blue Sheep (Pseudois nayaur) and White-lipped Deer (Cervus albirostris) which both have considerable populations in the region. The lowermost parts of the study site mainly consisted of farming areas in which major crops included barley, spring wheat, bean, colza, potato, and some vegetables. Mammalian predators in the study area included Siberian Weasel (Mustela sibirica), Red Fox (Vulpes vulpes), Tibetan Sand Fox (V. ferrilata), and Lynx (Felis lynx). Common avian predators are Magpie (Pica pica), Raven (Corvus corax), Golden Eagle (Aquila chrysaetos) and Sparrowhawk (Accipiter nisus).

\section{Field procedures}

We searched for nests from late April to late June each year. Except in 2005, when field work was less intensive, we searched systematically for nests across the whole study area with the assistance of 5-10 local people. Nest searches were carried out twice a week. We divided the study area between hillsides east and west of the main river (Gyama puchu) and scheduled two days on the east side and one day on the west side (with farmland) to cover the complete area. From the foot of slopes, or edges of farmland, nest searchers walked through the terrain with approx. 100-200 m distance (depending on the number of participants) and searched carefully for nests up to the top of slopes (or to the opposite edge of the farming area). Nests were found by flushing incubating females or by using sticks to lift vegetation and uncover nests which were left unattended. Presence of Tibetan Partridges was revealed by calling males in early spring and gave an indication of where nests would be situated. We did not observe Tibetan Partridges outside nest areas which would have indicated that some nests were overlooked. Nevertheless, it should be noted that, despite the large nest-searching effort, we cannot exclude the possibility that some nests were left undetected by us. The nest densities and nearest neighbour distances reported in this paper should therefore be considered minimum and maximum estimates, respectively. Nests were marked with small pieces of coloured plastic or cloth at a distance of $10 \mathrm{~m}$. In order to minimize disturbance, all nest-site characteristics were recorded after a clutch was completed or following depredation or desertion. We recorded the nest's geographical location and altitude with the GPS. Slope aspect (direction) and degrees of inclination were recorded using a compass.

To measure areas of the study site we first used the ruler tool in Google Earth to outline the whole study area and each habitat category. From the resulting aerial photo we used the software Adobe Photoshop CS5 Extended to measure areas. Distance was calibrated from the scale automatically generated by Google Earth. In this way we found the total study area to cover $22.9 \mathrm{~km}^{2}$ $\left(10.2 \mathrm{~km}^{2}\right.$ of north-facing slopes, $11.4 \mathrm{~km}^{2}$ of southfacing slopes, $1.2 \mathrm{~km}^{2}$ of farming area and $0.05 \mathrm{~km}^{2}$ of two small villages). In calculations of nest density we considered a marginal area of $2.6 \mathrm{~km}^{2}$ of the southfacing slope to be unsuitable habitat for the Tibetan partridge because there were almost no bushes growing there. In line with this assumption we did not record any nest in this area. The villages were also considered unsuitable breeding habitat for the species. Consequently, when calculating nest densities we use an area of $20.3 \mathrm{~km}^{2}$.

We sampled data on the general habitat within a $5 \times$ $5 \mathrm{~m}$ square around each nest, with the nest located in the centre. Within each of these squares we estimated percentage of bare ground and counted the number of plant species and the number of yak dung. We used the latter as a crude proxy for grazing intensity in our 
analyses. Both fresh and old dung was present in the nest areas but since we did not separate between them it is possible that the density recorded by us differed from the density experienced by the partridges prior to nest building. Yet, if trampling risk is important in nest site selection, the partridges may well use other cues than dung density to assess grazing intensity. It is therefore unknown whether varying dung age would bias the results in any way. The proportion of vegetation cover within each square was estimated by sight. Vegetation height $(\mathrm{cm})$ in the nest area was defined as the average of five measurements: in the centre and in each corner of the $5 \times 5 \mathrm{~m}$ sample areas. For each nest we recorded the species of plant that covered it and measured the plant's height and basal area. The latter was defined as length $\times$ width of the widest part of the foliage. For each nest we estimated the proportion that was covered by the foliage when viewing the nest from above (hereafter 'foliage cover'). We also measured the distance between nests and the nearest path or track. These were typically made by grazing animals and were distributed fairly evenly throughout the whole study area. To see if nest placement was non-randomly associated with variables of the nest habitat, we compared nest site information with similar data from control sites located $100 \mathrm{~m}$ from the nests in both a southern and a northern direction. At these two sites we located the nearest plant of the same species as the one which covered the focal nest and used it as a control plant. To get a comparable measure for foliage cover we here estimated how much of the nest would have been covered by the control plant if the nest was located at an equal position as for the nest plant, both with regard to distance from plant stem and direction. The control plant was also used as the centre point for a $5 \times 5 \mathrm{~m}$ control plot. We used the mean value of the two control measurements in analyses, making sample sizes equal among nest samples and control samples.

Distances between nests were measured to the nearest $1 \mathrm{~m}$ using a Nikon Laser 1200 range finder. A FLUKE ${ }^{\circ}$ digital thermometer was used to record soil temperature at a depth of seven $\mathrm{cm}$ from the surface within five $\mathrm{cm}$ from the rim of the nest cup, or from the stems of the control plants. We measured soil surface temperatures in the shade by placing the temperature sensor directly on the surface, whereas air temperature and relative air humidity was measured in the shade one meter above ground. For the latter we used a CEM DT-616 CT professional temperature-humidity meter. Soil humidity was measured from samples collected at random $10 \mathrm{~cm}$ away from the nest or at the same distance from the stem of the control plant. We weighed soil samples immediately upon sampling and again after being dried at $40^{\circ} \mathrm{C}$ for 50 hours. Soil humidity is defined as the percentage of mass lost from the original sample during drying. Since sampling of microclimatic data was not done at the same time these data could be biased by seasonal progress. Therefore we only analyse microclimatic data by paired comparisons in which the pairs of data from nest and control areas were taken at the same time. Measurements and recordings of all data were done by the same person (TD) in all three breeding seasons.

\section{Data analyses}

Statistical analyses were conducted using $\mathrm{R}$ version 2.11.1 ( $\mathrm{R}$ Core Team 2010). To explore if a bush species was over- or under-represented as nest cover we used a modified version of Ivlev's electivity index (Ivlev, 1961):

$$
E=\frac{r_{i}-n_{i}}{r_{i}+n_{i}}
$$

Here $E_{i}$ is the electivity index for species $i, r_{i}$ indicate percentage of species $i$ in sample of nest bushes, and $n_{i}$ indicate percentage of bush species $i$ available in the study area. The latter was estimated from the 24 samples collected in the general vegetation survey in the study area (see above). The value of $E_{i}$ varies between -1 and +1 . Positive values indicate a preference for the plant in question, whereas negative values indicate avoidance.

We here limited our investigation to focusing on bush species covering the nests and therefore excluded three nests placed below herbs in the calculation of electivity indices. In addition, two nests were placed below a mixture of $R$. primulaeflorum and P. fruticosa but where the former was the dominant species. Hence, we treated these nests as being covered by R. primulaeflorum. Similarly, one nest found under a mixture of $R$. sericea and $S$. pingii was treated as covered by $R$. sericea.

We also tested statistically if a given plant species was over- or under-represented as nest cover. We then compared the proportion of nests covered by that plant with its availability in the study area (the estimated proportion of all bushes from the general vegetation survey; see above. In these cases we used a Chi-square test with Yates' continuity correction or, when any of the cells in the $2 \times 2$ table were smaller than 5 (Siegel and Castellan, 1988), Fisher's exact test. Paired t-tests were used to test for differences between nest samples and control samples. Averages are given with standard deviations and all tests are two-tailed with alpha $=0.05$.

The study adhered to international guidelines for the treatment of animals in behavioural research (ASAB 2012).

\section{Results}

\section{Spatial distribution of nests}

Nests were situated at a mean altitude of $4445 \pm 184 \mathrm{~m}$ (range: $4129-4799 \mathrm{~m} ; n=56$ ). The spatial distribution of nests in the three different years is shown on Figure 2. 

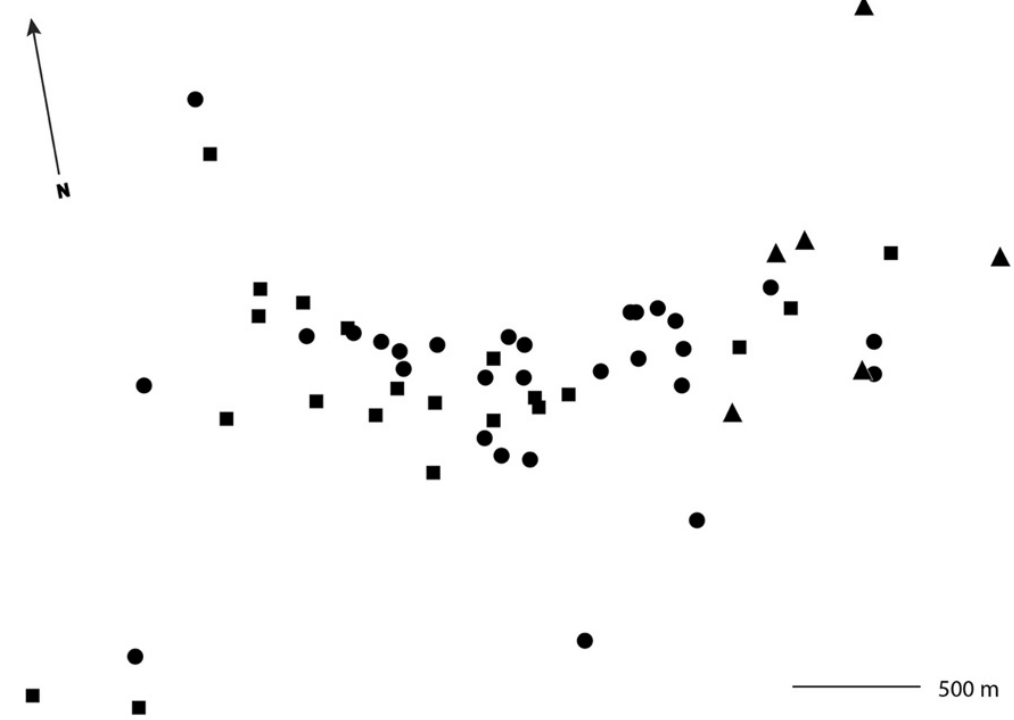

$500 \mathrm{~m}$

Figure 2 Distribution of Tibetan partridge nests $(n=56)$ in three different years in Gyama valley near Lhasa, Tibet. Nest locations are shown with different symbols for each year (triangle 2005, circle 2009, square 2010).

Excluding the year 2005 when nest searching was least extensive (6 nests found), the overall nest density was $1.43 / \mathrm{km}^{2}$ and $1.04 / \mathrm{km}^{2}$ in $2009(n=29)$ and $2010(n=21)$, respectively. Nest density was considerably higher on the north-facing slope $\left(2.35 / \mathrm{km}^{2}\right.$ in $2009,1.86 / \mathrm{km}^{2}$ in 2010$)$ than on the south-facing slope $\left(0.34 / \mathrm{km}^{2}\right.$ in 2009 and 0.11 / $\mathrm{km}^{2}$ in 2010). Excluding the year 2005 when many nests are likely to have gone undetected by us, the mean nearest neighbour distance between nests was $303.1 \pm 286.9 \mathrm{~m}$ (range 10-2000 m, $n=50$; 2009: $272 \pm 183 \mathrm{~m}, n=29$; 2010: $347 \pm 392 \mathrm{~m}, n=21)$.

\section{Vegetation at the nest sites}

A total of 11 plant species were recorded as nest cover (eight bush species and three herb species; Table 1) but $61 \%$ of the nests $(34 / 56)$ were placed beneath Potentilla fruticosa, a small deciduous shrub. When excluding the three nests found below herbs, P. fruticosa was used

Table 1 The use of different bush species as nest cover in the Tibetan Partridge in relation to their general occurrence in the study area

\begin{tabular}{|c|c|c|c|c|c|c|c|c|}
\hline \multirow[t]{2}{*}{ Plant species } & \multirow[t]{2}{*}{$n$} & \multirow{2}{*}{$\begin{array}{l}\text { Nest bush } \\
\text { height }(\mathrm{cm})\end{array}$} & \multirow{2}{*}{$\begin{array}{l}\text { Basal area } \\
\text { of nesting } \\
\text { bush }\left(\mathrm{cm}^{2}\right)\end{array}$} & \multirow{2}{*}{$\begin{array}{l}\text { Foliage cover } \\
\text { above nest (\%) }\end{array}$} & \multicolumn{2}{|l|}{ Availability } & \multicolumn{2}{|l|}{ Usage } \\
\hline & & & & & Bush density $/ \mathrm{m}^{2}$ & $\begin{array}{l}\text { Percent of } \\
\text { total bush } \\
\text { density }\end{array}$ & $\begin{array}{l}\text { Percent of } \\
\text { all nests }\end{array}$ & $\begin{array}{l}\text { Electivity } \\
\text { index }\end{array}$ \\
\hline Potentilla fruticosa & 34 & $51.21 \pm 13.11$ & $3402 \pm 2586$ & $64.12 \pm 15.3$ & 0.25 & 17.47 & 60.71 & 0.57 \\
\hline Rosa sericea & 2 & $65 \pm 49.5$ & $7967 \pm 3837$ & $80 \pm 0$ & 0.053 & 3.7 & 3.57 & 0.01 \\
\hline Rhododendron primulaeflorum & 9 & $68.88 \pm 19.37$ & $2372 \pm 1250$ & $72.78 \pm 12.53$ & 0.256 & 17.92 & 16.07 & -0.03 \\
\hline Caragana maximovicziana & 1 & 34 & 560 & 40 & 0.032 & 2.23 & 1.79 & -0.09 \\
\hline Berberis hemleyana & 1 & 102 & 620 & 70 & 0.045 & 3.47 & 1.79 & -0.3 \\
\hline Salix oritrepha & 4 & $87.25 \pm 51$ & $3227 \pm 1683$ & $60 \pm 20$ & 0.202 & 14.11 & 7.14 & -0.3 \\
\hline Sabina pingii & 1 & 45 & 32340 & 30 & 0.09 & 6.27 & 1.79 & -0.54 \\
\hline Spiraea tibetica & 1 & 51 & 3705 & 60 & 0.194 & 13.55 & 1.79 & -0.76 \\
\hline Rhododendron nivale & 0 & - & - & - & 0.219 & 15.34 & 0 & -1 \\
\hline Caragana jubata & 0 & - & - & - & 0.022 & 1.57 & 0 & -1 \\
\hline Cotoneaster microphyllus & 0 & - & - & - & 0.062 & 4.37 & 0 & -1 \\
\hline Total & & & & & 1.425 & 100 & 94.65 & \\
\hline Nests below herbs $(n=3)$ & & & & & & & 5.35 & \\
\hline
\end{tabular}

The electivity index varies from -1 to +1 where positive values indicate preference and negative values indicate avoidance. 
significantly more often as nest cover than one should expect from its estimated abundance in the study area (17\% of all bushes; $X^{2}=22.5, \mathrm{df}=1, p<0.001$; Figure 3 ). In contrast, only $7.2 \%$ of the nests were placed below a thorny bush (R. sericea: 3.6\%, C. maximovicziana: $1.8 \%$, $B$. hemleyana: $1.8 \%)$. Some plants had strongly negative electivity indices, indicating that they were avoided as nest cover. This was most notable for Rhododendron nivale, Caragana jubata and Cotoneaster microphyllus which all had an electivity index of -1 . However, only $R$. nivale was significantly less common as nest cover than expected from its abundance in the study area (Fisher's Exact Tests: $p=0.006$; C. jubata: $p=1, C$. microphyllus: $p=0.5$ ). The bush species $S$. tibetica had an electivity index of -0.76 which also indicates avoidance, but this was only nearly significant (Fisher's Exact Tests: $p=0.07$ ). No other species (e.g. S. oritrepha, S. pingii, R. sericea, R. primulaeflorum, $C$. maximovicziana and $B$. hemleyana) were more or less common as nest cover than expected from a random distribution $(p=0.36-1.0)$.

The basal areas of nest-covering bushes or herbs were wider than in control plants $\left(3696 \pm 4617 \mathrm{~cm}^{2}\right.$ and $1930 \pm$ $1297 \mathrm{~cm}^{2}$, respectively; $t=2.76, \mathrm{df}=110, p=0.007$ ) and such a difference was also evident in foliage cover above nests (nests: $64.8 \pm 15.7 \%$; controls: $38.9 \pm 11.4 \%$; $t=10.0$, $\mathrm{df}=110, p<0.001$ ). However, height of the nest covering bush did not differ from control bushes (nests: $56.7 \pm$ $23.3 \mathrm{~cm}$; controls: $55.9 \pm 19.5 \mathrm{~cm} ; t=0.2, \mathrm{df}=110, p=0.84$ ). The most common shrub species within the $5 \times 5 \mathrm{~m}$ squares surrounding nests were $P$. fruticosa, $R$. primulaeflorum, $R$. nivale, S. oritrepha and S. tibetica. Overall, these species constituted approx. 78\% (13.5-18.0\%) of the recorded bushes (Table 1). As shown in Table 2, total vegetation cover differed significantly between nest areas and control areas. When looking separately at herbs and bushes, nest areas showed a significantly lower herb cover than control sites while the opposite was true for bush cover. Moreover, the percentage of naked ground was lower around nests than in the control samples. There were no significant differences between nest areas and control areas in vegetation height or vegetation diversity (number of plant species).

\section{Other nest site characteristics and microclimatic conditions}

The average inclination of nest sites was $19.6 \pm 8.6^{\circ}$ (range $\left.10^{\circ}-50^{\circ}, n=56\right)$, which did not differ from control sites $\left(21.0 \pm 5.2^{\circ}\right.$; range $\left.7.5^{\circ}-35^{\circ} ; t=-1.02, \mathrm{df}=110, p=0.3\right)$. Nests were situated closer to paths than the random control plots (nests: $7.2 \pm 10.2 \mathrm{~m}$, range $0.5-54, n=56$; controls: $16.3 \pm$ $19.8 \mathrm{~m}$, range 1.5-115, $n=56 ; t=-3.04, \mathrm{df}=110, p=0.003)$. As we expected if nest sites were chosen to avoid trampling, the number of yak dung was significantly lower around nests than in control samples (nest areas: $1.9 \pm 1.7$, range $0-8, n=$ 56; control areas: $3.4 \pm 1.8$, range $0-9, n=56 ; t=-4.48$, $\mathrm{df}=$ $110, p<0.001)$.

Soil temperatures at the nests were significantly lower than in control samples (nests: $14.1 \pm 3.5^{\circ} \mathrm{C}$, controls: $15.7 \pm$ $\left.2.3^{\circ} \mathrm{C} ; t=-2.72, \mathrm{df}=110, p<0.001\right)$. However, there were no differences between these two samples in soil humidity (nest: $43.8 \pm 22.6 \%$; controls: $39.9 \pm 18.1 \%$ ), relative air humidity (nest: $44.9 \pm 17.1 \%$; controls: $48.6 \pm 14.9 \%$ ), air temperature (nest: $21.7 \pm 4.6^{\circ} \mathrm{C}$; controls: $22.2 \pm 4.1^{\circ} \mathrm{C}$ ),

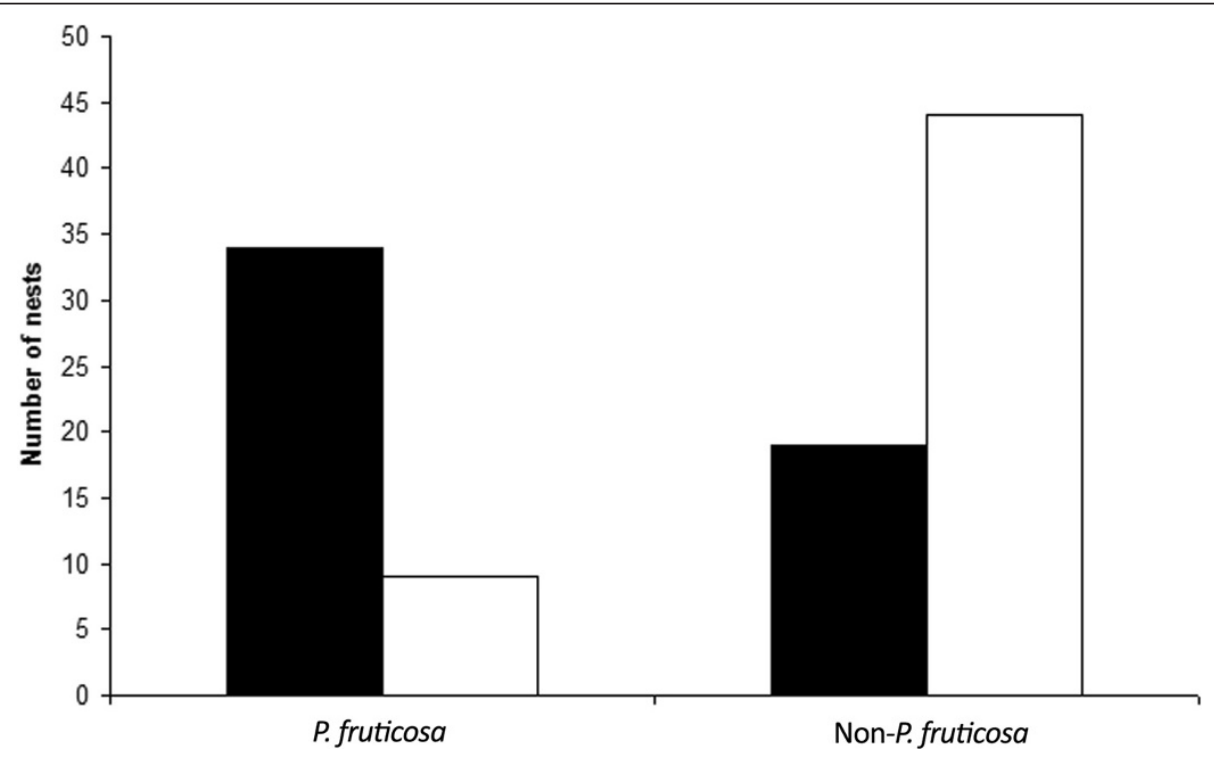

Figure 3 Preference of plants for nest concealment in the Tibetan Partridge. The observed numbers of nests covered by the flowering shrub Potentilla fruticosa and below all other species of shrub (black bars) compared with the expected numbers (white bars) from random vegetation samples in the study area $\left(X^{2}=22.5, \mathrm{df}=1, p<0.001\right)$. Nests situated under herbs $(n=3)$ have been excluded. 
Table 2 Differences in vegetation characteristics in $5 \times 5 \mathrm{~m}$ sample plots around nests of the Tibetan Partridge, and in control areas

\begin{tabular}{|c|c|c|c|c|c|}
\hline Characteristics & Nest & Control & $t$ & df & $p$ \\
\hline Vegetation cover (\%) & $82.89 \pm 10.64$ & $78.12 \pm 11.70$ & 2.26 & 110 & 0.03 \\
\hline Herb cover (\%) & $44.16 \pm 19.05$ & $53.28 \pm 16.09$ & -2.74 & 110 & $<0.001$ \\
\hline Shrub cover (\%) & $32.88 \pm 19.14$ & $18.57 \pm 8.99$ & 5.06 & 110 & $<0.001$ \\
\hline Bare ground (\%) & $11.84 \pm 7.11$ & $17.63 \pm 10.50$ & -3.42 & 110 & $<0.001$ \\
\hline Height of herbs (cm) & $9.29 \pm 2.97$ & $9.38 \pm 3.74$ & -0.15 & 110 & 0.88 \\
\hline Herb diversity ( $n$ species) & $10.14 \pm 3.01$ & $10.13 \pm 2.49$ & 0.03 & 110 & 0.97 \\
\hline Shrub height (cm) & $44.23 \pm 17.26$ & $41.26 \pm 16.44$ & 0.93 & 110 & 0.35 \\
\hline Shrub diversity ( $n$ species) & $2.73 \pm 1.15$ & $2.83 \pm 2.68$ & -0.25 & 110 & 0.80 \\
\hline
\end{tabular}

or soil surface temperatures (nest: $18.5 \pm 6.8^{\circ} \mathrm{C}$; controls: $20.3 \pm 5.6^{\circ} \mathrm{C} ; p=0.14-0.60, n=56$ for both nest and control samples in all cases).

\section{Discussion}

We found that nest sites of the Tibetan Partridge were associated with several habitat aspects, most notably the composition and characteristics of plant species. In contrast to the description by Madge and McGowan (2002), Caragana shrub was not an important part of the nest habitat in our study area. However, the two Caragana species that we recorded only constituted a small proportion of the total shrub flora in the study area and it is possible that Caragana shrub is more frequently used as nest habitat where such plants are more abundant. Nest sites also sometimes differed from our initial predictions based on adaptive hypotheses for nest site selection. Hence, this study adds some considerable new information about the breeding ecology of Tibetan Partridges.

Assuming that thorny bushes protect the nests from predators, we expected that Tibetan Partridges should prefer to nest in such shrub. However, the only plant species more often than random chosen as nest cover was the flowery shrub $P$. fruticosa. In our study area, thorny bushes were mainly distributed on the southfacing slope of the study area where only a small proportion of nests $(7 / 56)$ were found. This could either be an effect of birds avoiding areas with thorny bushes in general or that there were other unknown habitat characteristics, independent of the thorny bushes, which made the south-facing slope less suitable as nesting area. Compared with $R$. nivale which was clearly avoided as nest cover, or many other bush species in the study area, we are unable to point out any obvious differences in qualitative properties that would make $P$. fruticosa superior as nest cover. Hence, we can only speculate on the advantages of placing nests under this plant. One possibility is that the incubating hen's plumage generally makes a better camouflage when situated below P. fruticosa than below other plants. For instance, in a related species, the Grey Partridge (Perdix perdix), the preferred nest habitat contains much dead grass and leaf litter which probably makes the incubating hen hard for predators to see and thus has a positive effect on nest survival (Rands, 1988, Potts, 2012). A possible reason for this is that the substrate of the nest surroundings is used for covering eggs during the laying period, thus reducing their visibility (Rands, 1988). Such egg covering occurs also in Tibetan Partridges (own unpublished data) and it is possible that more substrate for egg covering is available below P. fruticosa.

Several findings in this study indicate that Tibetan Partridges prefer nest sites in relatively dense vegetation. The proportion of shrub cover was higher and herb cover lower around nests than in control areas, and the nest bush's basal area was larger in nest-covering plants than in control samples of the same plant species. These findings are in accordance with the hypothesis that birds select nest sites according to the potential for nest concealment. Hiding the nests for predators should be of utmost importance to most birds, and with a clear selective advantage due to the positive effect on survival in eggs, chicks and incubating parents (Martin, 1993). Studies looking for positive effects of placing nests inside or below dense foliage have provided mixed results, though, and it is possible that also other factors such as parental behavior and the composition of the predator community work and interact in producing nest predation risks (Dion, et al. 2000; Remeš, 2005; Lima, 2009). Hence, more studies are warranted in the Tibetan Partridge to see if nest plant characteristics and nest cover influence predation risk in the species.

The finding that Tibetan Partridges nested in vegetation rich areas might appear to contradict $\mathrm{Lu}$ et al. (2003) who reported that nest site vegetation was sparser than in control sites. We note that most nests in our study were situated on a north-facing slope with richer vegetation than in the south-facing slope studied by $\mathrm{Lu}$ et al. (2003; pers. obs.). Hence, it is possible that the composition of plant species differed in the two study 
areas in ways that could have affected the birds' preferences for vegetation density. Both studies suggest, however, that cases where the partridges place their nests on bare soil (Johnsgard, 1988) are exceptional. As discussed above for nest plant properties, preference for dense shrub might be adaptive by reducing nest predation risks. However, the picture could also be more complicated. For instance, hiding the nest in dense vegetation may impede visibility for the incubating bird and thus make it more vulnerable to approaching predators (Götmark et al. 1995; Burhans and Thompson, 2001; Magaña et al. 2010). Evidence for this hypothesis comes from another gallinaceous species, the North-American White-tailed Ptarmigan (Lagopus leucurus), where well-concealed nests are less often detected by predators but more risky for incubating females (Wiebe and Martin, 1998). Moreover, nest sites which are optimal in terms of predation risk may provide sub-optimal thermal conditions (Marzluff, 1988; Amat and Masero, 2004; Eggers et al. 2006). Finally, Tibetan Partridges typically escape a potential danger by running on the ground (Madge and McGowan, 2002; pers. obs.) and a critical characteristic of the nest habitat may therefore be that there is enough room for the birds to run in without drawing attention.

Two of our findings could indicate that grazing animals influenced nest site selection in the Tibetan Partridge. First, in accordance with $\mathrm{Lu}$ et al. (2003) we found that nests were situated closer to paths made by such animals than expected from a random distribution. This could not result from sampling bias, since nest searching was not restricted to areas along paths. In fact, the main direction of nest searches went from the bottom to the top of hill sides, crossing paths which generally ran more perpendicular to the slope directions. Female partridges may enhance reproductive success and own survival by securing easily accessible escape routes on paths in the case of approaching predators $(\mathrm{Lu}$ et al. 2003). As mentioned above, openings in the nest shrub may also secure better views of the surroundings so that incubating females get more time to react to any potential threats (Götmark et al. 1995). However, it is likely that nests situated too close to a path would be easier for predators to find, so there may be an optimal distance within which nests should be placed. Second, the amount of yak dung at the control sites was significantly higher than in nest patches, possibly indicating that nest sites were selected in relation to trampling risk. However, we cannot rule out other possible explanations for this pattern, for instance that protection from yak is simply a secondary benefit of nesting in relatively dense shrub and that e.g. reducing predation risk is the main factor determining nest site choice. We observed nest trampling by Yak in one of the nests in this study (unpublished data), showing that it is a possible threat for ground nesting birds in this region. However, the sample is limited and more investigations on trampling of bird nests in pastoral landscapes of the Himalayas would be useful.

Of the examined microclimatic factors, the only one that differed between nest sites and control sites was soil temperature which was lower in the former. This could perhaps be explained by the denser vegetation around nests which shaded the ground. Since our measurements are only snapshots of the temperature and humidity conditions, it is possible that more detailed monitoring would have revealed additional differences in microclimate around nests. Also, our assumption that birds would select warmer nest sites may be wrong. The lower density of nests on south-facing slopes could for instance have been caused by a presumably warmer climate there than on north-facing slopes. Even if climatic conditions per se may not be critical for the birds, reduced evapotranspiration, generally higher humidity and colder air could have caused better conditions for vegetation growth on the north-facing slope Kutiel (1992) resulting in a more favorable partridge habitat there.

\section{Conclusions}

Our findings indicate that the opportunity for nest concealment is an important quality of the nest habitat in Tibetan Partridges, yet it is unclear why the species should prefer $P$. fruticosa as nest cover. Nest sites may be chosen to secure escape exits in the case of approaching predators and it is also possible that birds choose nest sites where the risk of trampling by livestock is redeuced. Finally, Tibetan Partridges may select nest sites according to micro-climate, either directly or indirectly through climate-related differences in shrub vegetation. Both microclimate and vegetation could explain why more nests were found on the north-facing slope in this study, but comparisons of nest density should be done for more than one pair of slopes to see if this is a general situation in the species.

\section{Competing interests}

The authors declare that they have no competing interests.

\section{Authors' contributions}

Conceived and designed the study: DT. Performed the field work: DT. Analyzed the data: DT, GH, TL. Wrote the paper: DT, GH, TL. All authors read and approved the final manuscript.

\section{Acknowledgements}

We are grateful to the late Torstein Solhøy for initiating the project and for help in the early stages of this work. We also thank the people in the Tukchak village and Basang, Lhakdor and Purbu for their kind assistance during field work. Gaute Grønstøl and Tina Sugunthi provided useful comments on earlier versions of the manuscript. The study was funded by the Network for University Co-operation Tibet-Norway.

\section{Author details}

${ }^{1}$ Department of Biology, University of Bergen, Box 7803, 5020 Bergen, Norway. ${ }^{2}$ Department of Biology, Faculty of science, Tibet University, 850000 Lhasa, China. ${ }^{3}$ University Museum of Bergen, University of Bergen, Box 7800, 5020 Bergen, Norway. 
Received: 4 August 2014 Accepted: 8 August 2014

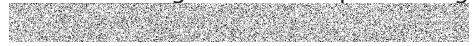

\section{References}

Amat J, Masero JA (2004) Predation risk on incubating adults constrains the choice of thermally favourable nest sites in a plover. Anim Behav 67:293-300

ASAB (2012) Guidelines for the treatment of animals in behavioural research and teaching. Anim Behav 83:301-309

Beintema AJ, Müskens GJDM (1987) Nesting success of birds breeding in Dutch agricultural grasslands. J Appl Ecol 24:743-758

BirdLife International (2014) Species factsheet: Perdix hodgsoniae. [http://www. birdlife.org on 07/01/2014]

Burhans DE, Thompson FR (2001) Relationship of songbird nest concealment to nest fate and flushing behavior of adult. Auk 118:237-242

D'Alba L, Spencer KA, Nager RG, Monaghan P (2011) State dependent effects of elevated hormone: Nest site quality, corticosterone levels and reproductive performance in the common eider. Gener Compar Endocrinol 172:218-224

Deeming DC (2002) Avian Incubation: Behaviour, Environment, and Evolution. Oxford University Press, Oxford

del Hoyo J, Elliott A, Sargatal J (1994) Handbook of the Birds of the World, vol 2. Lynx Edicions, Barcelona

DeLong AK, Crawford JA, Delong DC Jr (1995) Relationships between vegetational structure and predation of artificial Sage Grouse nests. J Wildlife Manage 59:88-92

Dion N, Hobson KA, Larivière S (2000) Interactive effects of vegetation and predators on the success of natural and simulated nests of grassland songbirds. Condor 102:629-634

Dorge T (2014) Nesting ecology in a Himalayan gallinaceous bird, the Tibetan Partridge (Perdix hodgsoniae). PhD thesis. University of Bergen,

Eggers S, Griesser M, Nystrand M, Ekman J (2006) Predation risk induces changes in nest-site selection and clutch size in the Siberian jay. Proc R Soc B 273:701-706

Filliater TS, Breitwisch R, Nealen PM (1994) Predation on Northern Cardinal Nests: Does choice of nest site matter? Condor 96:761-768

Götmark F, Blomqvist D, Johansson OC, Bergkvist J (1995) Nest-site selection: a trade-off between concealment and view of the surroundings? J Avian Biol 26:305-312

Ivlev VS (1961) Experimental Ecology of the Feeding of Fishes. Yale University Press, New Haven, Connecticut

Johnsgard PA (1988) The Quails, Partridges and Francolins of the World. Oxford University Press, Oxford

Kim S-Y, Monaghan P (2005) Effects of vegetation on nest microclimate and breeding performance of lesser black-backed gulls (Larus fuscus). J Ornithol 146:176-183

Koerth BH, Webb WM, Bryant FC, Guthery FC (1983) Cattle trampling of simulated ground nests under short duration and continuous grazing. J Range Manage 36:385-386

Kutiel P (1992) Slope aspect effect on soil and vegetation in a Mediterranean ecosystem. Israel J Botany 41:243-250

Larison B, Laymon SA, Williams PL, Smith TB (1998) Song Sparrows vs. cowbird brood parasites: impacts of forest structure and nest-site selection. Condor 100:93-101

Lima S (2009) Predators and the breeding bird: behavioral and reproductive flexibility under the risk of predation. Biol Rev 84:485-513

Loye JE, Carroll SP (1998) Ectoparasite behavior and its effects on avian nest site selection. Ann Entomol Soc Am 91:159-163

Lu X, Gong GH, Ci R (2003) Reproductive ecology of the Tibetan partridge Perdix hodgsoniae in Lhasa Mountains. Tibet J Yamashina Inst Ornithol 34:270-278

Lu X, Ke D, Ma X, Gong G, Yu T (2010) Nesting records of 20 bird species in Lhasa region, Tibet. Chinese Birds 1:167-174

Madge S, McGowan P (2002) Pheasants, Partridges and Grouse. Cristopher Helm, London

Magaña M, Alonso JC, Martin CA, Bautista LM, Martin B (2010) Nest-site selection by Great Bustards Otis tarda suggests a trade-off between concealment and visibility. Ibis 152:77-89

Martin TE (1993) Nest predation and nest sites: new perspectives on old patterns. Bioscience 43:523-532

Martin TE (1995) Avian life history evolution in relation to nest sites, nest predation, and food. Ecol Monogr 65:101-127

Marzluff JM (1988) Do pinyon jays alter nest placement based on prior experience? Anim Behav 36:1-10
Montevecchi MA (1978) Nest site selection and its survival value among laughing gulls. Behav Ecol Sociobiol 4:143-161

Paine L, Undersander DJ, Sample DW, Bartelt GA, Schatteman TA (1996) Cattle trampling of simulated ground nests in rotationally grazed pastures. J Range Manage 49:294-300

Potts GR (2012) Partridges. Collins, London

R Core Team (2010) R: A Language and Environment for Statistical Computing. R Foundation for Statistical Computing, Vienna, Austria (http://www.R-project. org)

Rands MRW (1988) The effect of nest site selection on nest predation in Grey Partridge Perdix perdix and Red-legged Partridge Alectoris rufa. Ornis Scand 19:35-40

Remeš V (2005) Nest concealment and parental behaviour interact in affecting nest survival in the blackcap (Sylvia atricapilla): an experimental evaluation of the parental compensation hypothesis. Behav Ecol Sociobiol 58:326-333

Siegel S, Castellan NJ (1988) Nonparametric Statistics for the Behavioral Sciences. McGraw-Hill International Editions, New York

Storey AE, Montevecchi WA, Andrews HF, Sims N (1988) Constraints on nest site selection: A comparison of predator and flood avoidance in four species of marsh-nesting birds (Genera: Catoptrophorus, Larus, Rallus, and Sterna). J Comparat Psychol 102:14-20

Tryjanowski P, Kuzniak S, Diehl B (2000) Does breeding performance of Redbacked Shrike Lanius collurio depend on nest site selection? Ornis Fennica 77:137-141

Watson M, Wilson JM, Koshkin M, Sherbakov B, Karpov F, Gavrilov A, Schielzeth H, Brombacher M, Collar NJ, Cresswell W (2006) Nest survival and productivity of the critically endangered Sociable Lapwing Vanellus gregarious. Ibis 148:489-502

Wiebe K, Martin K (1998) Costs and benefits of nest cover for ptarmigan: changes within and between years. Anim Behav 56:1137-1144

doi:10.1186/s40657-014-0005-7

Cite this article as: Dorge et al:: Nest distribution and nest habitat of the Tibetan Partridge (Perdix hodgsoniae) near Lhasa, Tibet. Avian Research 2014 5:5.

\section{Submit your next manuscript to BioMed Central and take full advantage of:}

- Convenient online submission

- Thorough peer review

- No space constraints or color figure charges

- Immediate publication on acceptance

- Inclusion in PubMed, CAS, Scopus and Google Scholar

- Research which is freely available for redistribution 